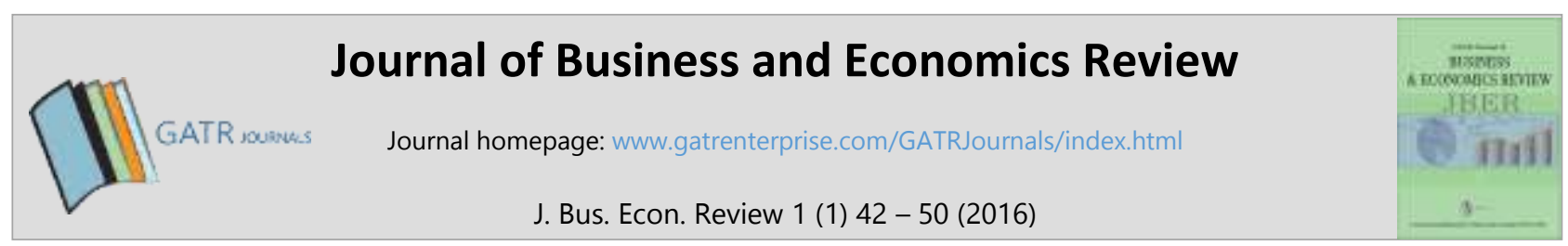

\title{
The Placement Model for Indonesian Migrant Workers to Improve their Economic Welfare
}

\author{
Izza Mafruhah ${ }^{1 *}$, Nurul Istiqomah ${ }^{2}$, Nunung Sri Mulyani ${ }^{3}$ and Mugi Rahardjo ${ }^{4}$ \\ 1,2,4 Departement of Economic Development, Faculty of Economic and Business Sebelas Maret University, Indonesia \\ ${ }^{3}$ Center for Regional Policy and institutional Studies, Institute for Research and Community Service, Sebelas Maret University, \\ Surakarta, Indonesia,
}

\begin{abstract}
Objective - Indonesian Migrant Workers (TKI) have an important role in employment. In 2015, the number of migrants who worked abroad reached more than seven million people. Despite the huge number, Indonesian Migrant workers are prone to problems encompassing: pre-placement, placement, and post-placement phases. This study aims to analyze the priority factors affecting migrant workers at the three phases as a means to determine their work success. This study also aims to develop a placement model for Indonesian migrant workers especially in the formal sector so as to better improve their welfare.

Methodology/Technique - To build a model of migrant workers for the formal sector, this study uses two approaches: 1) Analytical Hierarchy Process (AHP) and 2) Qualitative Analysis which is based on in-depth interviews and focused group discussions.

Findings - The results showed that the priority factors that determine migrant workers' success include the three phases: the placement phase with a value of 0.523198; the pre-placement phase with a value of 0.289185 ; and the post-placement phase with a value of 0.187617 . In addition, it is found that the formal sector placement policy should be conducted in collaboration with the countries of destination, especially in the recruitment patterns, the substance of contract, and legal protection. It is suggested that countries that have cooperated in the placement of migrant workers with the G-to-G (Government to Government) model is Japan and South Korea while the placement to other countries of destination is done with the B-to-B (Business to Business) model.
\end{abstract}

Novelty - The main model recommended in this study is the $G$ to $G$ model which should be implemented in order to safeguard migrant workers as well as to ensure that this model is formulated in policies and government regulations.

Type of Paper: Empirical.

Keywords: Indonesian Migrant Workers; AHP; G-to-G; B to B; PPTKIS.

JEL Classification: D61, J15.

\section{Introduction}

The term migration can mean both legal and illegal movements such as refugees of political, security and natural disasters or refugees of economic factors. Looking from the economic perspective, economic migration

\footnotetext{
* Paper Info: Received: September 8, 2016

Accepted: December 13, 2016

* Corresponding author:

E-mail: izza_wisnu@yahoo.com

Affiliation: Faculty of Economic and Business, Sebelas Maret University, Indonesia
} 
is often described as the movement of people from areas with lower economic growth rate to regions with higher economic growth rates. This is because higher economic growth provides a significantly greater employment opportunity for the workforce from lower economic growth countries (IOM 2010). Migration may cause dependence between countries of destination and origin. For instance, in destination countries, migrant workers act as a productive workforce that can be used for economic activities whereas in the country of origin, migrant workers would reduce the unemployment rate significantly (Bouguen et al. 2014). The main reason for migrant workers to work abroad is the economic motivation to earn higher income which can be sent home to the family in the country of origin. This is usually referred to as remittance. There are two motives for remittance. First, altruism or in other words, migrant workers' concern towards their family in the country of origin. Such a remittance can improve their family's economic welfare. Evidence shows that migrant workers send a greater amount of money home to the country of origin when economic conditions deteriorate. This is with the hope that their family consumption remains intact during an economic turmoil. (Presbitero et al. 2014). Second, self-interest or motivation out of their own interest. Migrants who are motivated by selfinterest will send the money for investment purposes. This shows a positive relationship between remittances and domestic economic activities (Lueth \& Ruiz-Arranz 2006).

Indonesia is a country with a relatively large number of migrant workers abroad. The number of Indonesian Migrant Workers is increasing from year to year, and this is expected to reduce unemployment in Indonesia. Currently, there are nearly seven million Indonesian migrant workers spread around the world. The increase in the number of migrant workers provides a positive impact for the home country in the form of increased remittances sent into Indonesia. In 2014, remittances sent to Indonesia amounted to IDR 105.9 trillion or about 6\% of the State's Budget. The figure increased to IDR 120 trillion in 2015. This amount is exceptionally high. However, when probed deeper, the condition is less encouraging. It was noted that about seven million migrant workers were only able to send 120 trillion in the first year. This means that each migrant worker was only able to send about IDR 17.1 million per year or 1.4 million IDR per month. The total remittance is actually lower than the amount Philippine migrant workers remit home. Philippine migrant workers were able to send around IDR 19 million per month or about 10\% of the state's economy (BNP2TKI 2015), suggesting that they are bigger contributors to their home country's economy.

A far more alarming condition had happened before 1980 until 2010 when the number of migrant workers in the informal sector was much higher than those in the formal sector. After 2010, the number of migrant workers in the formal sector became slightly higher. Data taken from the National Agency for the Placement and Protection of Indonesian Migrant Workers (BNP2TKI) show that from 2004 to 2010, the percentage of workers in the formal sector was below 30\%. In 2011, the number had increased to 45\%, and in 2012 and 2014, it reached more than 50\%. Workers in the informal sector continue to be reduced because of several disadvantages such as the work position offered, often categorized as 3D (Dangerous, Dirty, and Difficult). Another drawback of the informal sector is the low salary and lack of legal protection and advocacy for migrant workers. The Indonesian government has attempted to reduce the number of informal workers by implementing the policy of the Minister of Labor about migrant workers' moratorium on individual users of domestic workers. The policy consists of hard policy in the form of cessation of migrant worker placement in 21 countries in the Middle East, and soft policy in the form of tightening the placement in the Asia Pacific region. Violation of this policy will be considered a criminal offense of trafficking (BNP2TKI 2015).

There are three main points noted in the problems experienced by migrant workers: the pre-placement (before their departure abroad), the placement (after their arrival abroad), and the post-placement (after their return to the home country and becoming former migrant workers). Based on these points, the current study seeks to analyze the most appropriate placement model that can be used for migrant workers especially in the formal sector. In that regard, the objectives of this study are:

1. To determine the factors that influence the pre-placement, placement and post-placement of migrant workers;

2. To identify a placement model which can be implemented for prospective migrant workers. 


\section{Literature Review}

Migration is a highly selective process that affects individuals. This can be viewed through the characteristics of particular economic status, social, educational, and demographic patterns. In this regard, the effects of environmental, economic and non-economic factors on each individual is also different. (Budi Rahayu, 2013). Non-economic factors, among others, can also influence people to migrate and these include: 1) Social factors; 2) Physical factors (including the effects of climate and natural disasters such as floods and droughts); 3) Demographic factors; 4) Cultural factors; and 5) Communication factors (including the quality of the entire transport facilities, the education system and the impact of modernization).

For the purpose of explanation, the theory of neoclassical macro economic is used to understand the process and movement of migrant workers from countries with excess labor but lack capital to countries that lack manpower but have excess capital. This theory does not indicate why an individual decides to move or even the way the person moves. The theory of the neoclassical micro economics discusses the migration decisions of individuals and it also claims that the productive migrant would consider the costs and benefits of the area of origin (Hugo 1993) before moving.

The theory of the household economic states that the flow of migration determines household strategies in maximizing revenue and minimizing risk and eliminating the constraints of market failure. This theory is used to explain how migration decisions are not made by individuals but by larger units such as family or households where people think and do many activities collectively (Massey et al. 1993; Massey, 1999a; Hugo, 1998).

The theory of the labor market states that labor migration is driven by the high market demand. The country of periphery remains a poor country because the labor that goes abroad are workers with high productivity so the people who live in the country of origin are those with low productivity. Therefore, the remittances sent by migrant workers would mostly be used for household consumptions (Massey 1999b; King, 2012; Bouguen et al., 2014).

The global remittances made by migrant workers from abroad or developing countries show an increase. In 2002, remittance reached USD 88 billion; it then increased to 93 billion in 2003 (Carling, 2005), and the amount reached USD 325 billion in 2010 (Imai, Gaiha, Ali, \& Kaicker, 2014). Remittances have had positive impacts and among others:

(1) The credit rating of a country will increase;

(2) The remittance will support the stability of foreign currency;

(3) Remittance can reduce investor panic;

(4) Remittance will support the balance of payments, and

(5) Remittance will encourage development projects (Taylor 2006).

The growth of remittance, over the years, have had an impact on the economy in three ways. The first impact is that it affects the accumulation of capital, increasing the rate of accumulation of physical and human capital, and pushing down the cost of capital in the recipient country. This means that the additional remittances have a role in stabilizing the economy or in reducing volatility, thereby reducing the risk premium investors' demand. The second impact is that there will be a change in labor force growth. In this regard, remittances have a negative impact on employment in the country of origin because it would increase consumption and there will be less work for the recipient because most of the cost of the recipient's life has been fulfilled. The third impact is that remittances have an impact on the efficiency of investment by affecting the growth of the TFP, depending on who makes the investment decisions (Imai et al. 2014).

Besides remittances, another important factor noted in migrant workers' workforce is that it increases human capital. Dustmann, Fadlon, and Weiss (2011) had conducted a study using the basic theory of Roy's (1951) dynamic model in which a worker was shown to have two different skills which can be coupled with learning by doing. The results showed that migrants who return to their home country will be able to implement the acquired skills so as to become a brain gain for the home country. This thus, increases the accumulation of 
human capital. In fact, full migrants can mitigate the brain that will improve human capital skills and this is especially so for workers in the country of origin (Dustmann \& Glitz 2011). In another study, Pia Pinger stated that there is a difference between temporary migrants and permanent migrants. Temporary migration is beneficial for developing countries because it encourages the upgrading of skills, and remittances and savings (Pinger 2010).

Dustmann and Glitz (2011) stated that the economic success of migrants in destination countries is motivated by education where the migrant worker is able to transfer knowledge and skills which he/she had gained; this is an investment. Another resultfor economic success is traced to the migrant worker's desire to acquire skills in destination countries so that he/she has a higher return when he/she returns to the country of origin (Dustmann \& Glitz 2011).

The former migrant worker has more value because it seems that this theory has worked in countries with more advanced technologies and production processes. In this manner, the migrant worker can play a role in addressing human capital constraints. If the new knowledge acquired from abroad can be transferred and used productively in the country of origin, migrants would decide to come back, for example student migration (Dustmann \& Kirchkamp 2002; Marchand et al., 2013). On the other hand, migration also has a fixed negative effect on human capital. This occurs when the skills and education levels of the migrants at their destination country is fixed or below the level of education, skills and capacities in the destination country (Dequiedt \& Zenou 2013).

\subsection{Indonesian Migrant Workers}

Law No. 39 (2004) that defines Indonesian Migrant Workers as any Indonesian citizens who are qualified to work abroad in the employment relationship for a given period of time with pay (Republic of Indonesia, 2004). As described in the previous section on migration, Indonesian workers seeking employment abroad are, in general, poor people who go abroad to work for economic reasons. Most Indonesian workers who go abroad to work are the backbone of their families so their remittances are often sent home to families in Indonesia.

A specific problem for Indonesian migrant workers is the relatively low salary they receive, compared to migrants from other countries. This issue is caused by three main factors. First, most workers serve as a weaker level of the human resources due to their lower education levels. Second, the majority of migrant workers who work abroad have low work skills and ability. Third, the communication ability of migrant workers is weak as most of them have not received effective communication skills' training. These three factors can cause migrant labor to only acquire jobs in the informal sector or in the 3D (dirty, dangerous, and difficult) positions.

The placement of workers overseas as migrant workers is not only due to economic issues. There are, in fact, other social and cultural issues which require more in-depth discussions. Migrant workers are not just about the sending out of workers physically to other countries to work. In fact, when migrant workers go abroad, they are simultaneously being exposed to differences such as their own culture and the culture of others that is beyond their understanding. This aspect of the cultural issue is a potential cause of problems for many migrant workers particularly through the process of acculturation and enculturation. Both of these processes can incur both positive and negative consequences. Migrant workers often work under contracts. When these migrant workers have successfully completed their contract without a problem, they tentatively also manage to improve their economic welfare. Nonetheless, the problem arises when they are unable to complete their contracts due to various issues which may include the changing patterns of gender relations and/or relations with socio-cultural inequality in that particular country they work in. Moreover, if these migrant workers fail to complete the contract and they return home before the contract expires with issues such as psychological problems and traumas, these migrant workers go through an even more severe process of stabilization. The BNP2TKI data have suggested that these problems are mostly encountered by migrant workers in the informal sector such as domestic helpers. Therefore, it is necessary to do research on the model of the placement of migrant workers in the formal sector 


\section{Research Methods}

This study combines the quantitative and qualitative method of analyzing data. First, the study uses primary data collected from 150 former migrant workers who also served as respondents. The other respondents noted in this study are the BNP2TKI and PPTKIS officials. The analytical tools used in this study include the Analytical Hierarchy Process and the Granger Causality test used to assess in-depth interviews and focus group discussions. To answer the first research objective, the Analytical Hierarchy Process (AHP) is used. The AHP helps to break down complex problems into hierarchical groups. Through the AHP, the weighting factors or variables can then be carried out in accordance with human perception which is expected to describe the actual conditions (Kuncoro, 2014). To answer the second research objective, documents and interviews were used to clarify the existing placement model. This is followed by a focus group discussion (FGD) as a means to evaluate the placement model. The first FGD's objective is to obtain input in developing the model of migrant workers in the formal sector. Result of the first FGD will be processed with literature data, results of in-depth interviews and the model of placement of migrant workers that have been done, to be arranged into a model of migrant workers in the formal sector. The second FGD aims to confirm the results of the model and the application efforts in the placement process. Once placement model gets feedback and fit, then it will be proposed to the BNP2TKI. The problems noted in this study are divided into two stages of priorities and they are then arranged in the tree problems as shown in Figure 1.

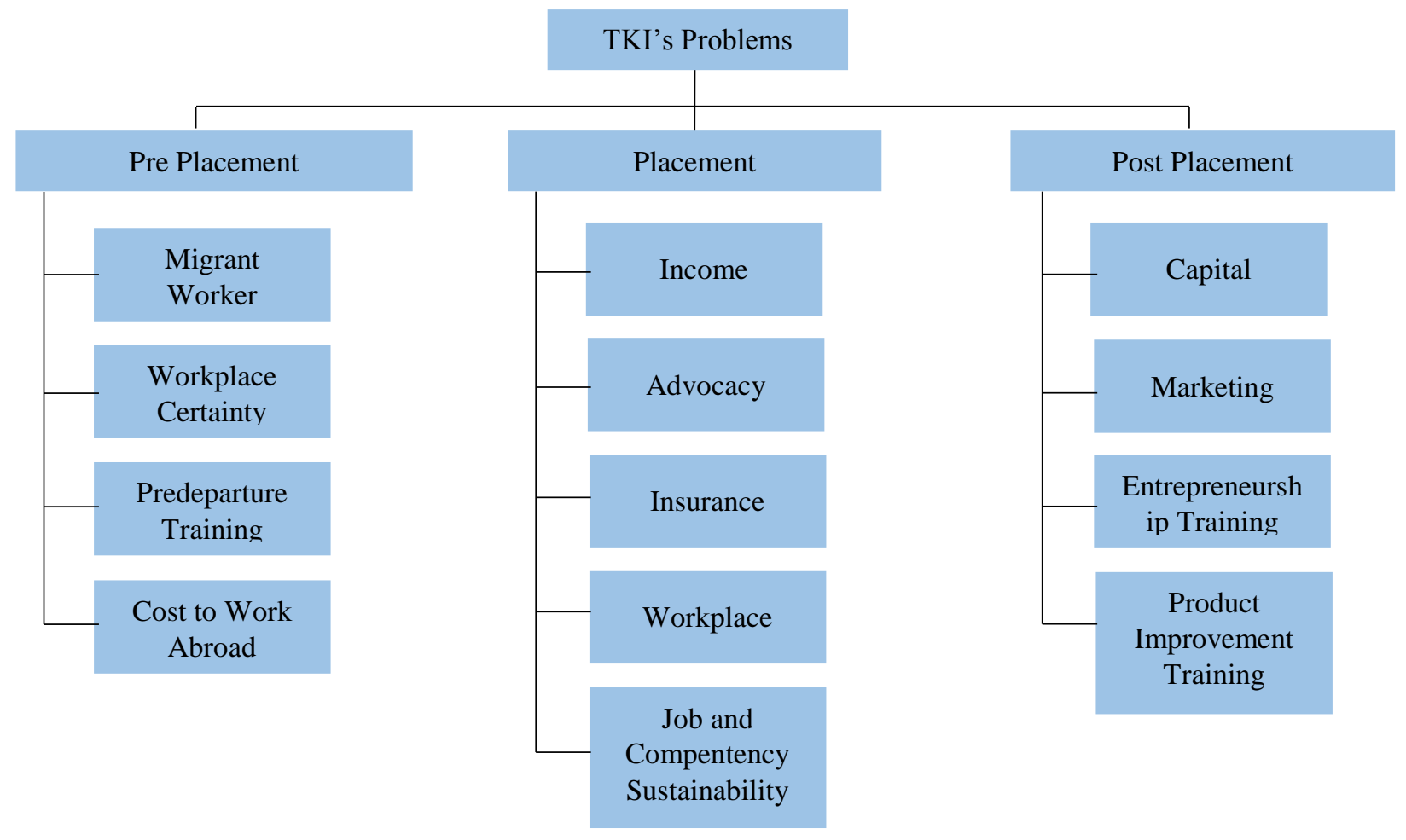

Figure 1. Analytical Hierarchy Process

\section{Discussion}

As analysis of data show, Indonesian Migrant Workers amount to a total of seven million, with majority of them having low education. Data from the BNP2TKI also indicate that the education of these migrant workers have been dominated by junior high and elementary education levels only. In 2012, migrant workers with a basic education of nine years totaled $69.19 \%$, and this then declined to $68.66 \%$ in 2013 . However, this figure 
shot up to $70.15 \%$ in 2014 and the figure increased to $72.21 \%$ in 2015 . The low educational level of these migrants suggest that they can only work as labor migrants in the informal position.

The BNP2TKI data stated that there were 21 positions for migrant workers in the formal and informal sectors abroad. However, over the years, a dominant position that stood out specifically for Indonesian migrant workers is that of the domestic worker with a percentage of $45.5 \%$ in 2011 . This figure is due to the relatively low education level of workers who can only work as domestic helpers. To overcome this issue, the Indonesian government has developed several policies with the hope that it can reduce the number of workers working in the informal sector. This include developing a moratorium of sending workers as domestic workers.

The next objective of this study is to evaluate the workers placement model. As the first objective of this study was to determine the factors that influenced migrant workers at the different points of placement, this study will thus, focus on the phases of pre-placement, placement and post-placement as a means to analyze the variables of derivatives. Data were processed by the AHP and the result showed that the respondents consider the point of placement as a key priority to be completed. The results indicated this pre-placement phase as a priority, with the value of 0.523198 , the second priority phase is during placement phase which has a value of 0.289185 and finally, the post placement phase which has a value of 0.187617 , as a third priority. In detail the derivative factors are shown in Table 1:

Table 1. AHP Result

\begin{tabular}{|c|c|c|c|}
\hline NO & \multicolumn{2}{|c|}{ PROBLEM } & VALUE \\
\hline \multirow[t]{6}{*}{1} & \multicolumn{3}{|l|}{ Placement } \\
\hline & (i) & Income & 0,3298 \\
\hline & (ii) & Advocacy & 0,2086 \\
\hline & (iii) & Insurance & 0,1921 \\
\hline & (iv) & Workplace & 0,1353 \\
\hline & (v) & Job competency suitability & 0,1342 \\
\hline \multirow[t]{5}{*}{2} & \multicolumn{3}{|c|}{ Pre Placement } \\
\hline & (i) & protection of migrant workers & 0,3642 \\
\hline & (ii) & the certainty of the workplace & 0,2349 \\
\hline & (iii) & pre-departure training & 0,2153 \\
\hline & (iv) & the cost for becoming a migrant worker & 0,2034 \\
\hline \multirow[t]{5}{*}{3} & \multicolumn{3}{|c|}{ Post Placement } \\
\hline & \multicolumn{2}{|l|}{ (i) Capital } & 0,4789 \\
\hline & \multicolumn{2}{|c|}{ (ii) Marketing } & 0,3264 \\
\hline & \multicolumn{2}{|c|}{ (iii) Entrepreneurship training } & 0,2076 \\
\hline & \multicolumn{2}{|c|}{ (iv) Producy improvement training } & 0,0869 \\
\hline
\end{tabular}

Source : Data processing, 2016

From the outcome noted, it is deduced that in the case of Indonesian Migrant workers, the placement is the most important phase while the income desired is the next most important variable. This is then followed by advocacy and insurance. Therefore, the placement noted in the formal sector with higher income and better 
protection should be the first consideration of a policy to consider while determining the model of migrant workers placement.

As can be seen, placement is the first priority for the Indonesian migrant workers because it will determine the success of migrant workers in the next period. The period of placement is vulnerable to act on criminality and human trafficking. Based on the various bad experiences suffered by migrant workers, the Indonesian government has then developed some restriction policies of sending workers to work abroad. Of course, these steps need to be followed by other policies because unemployment in Indonesia is still high. The important policy must be taken to evaluate the TKI placement pattern and then to look for the best placement model.

The placement of migrant workers in destination countries uses different patterns, but such patterns, basically consists of the G-to-G (Government to Government) model, in other words, the migration purpose is conducted by the government. next to follow is the $\mathrm{G}$ to $\mathrm{B}$ (Government to Business) model and finally the Bto-B (Business to Business) model which is conducted between the PPTKIS and private distributors of migrant workers in destination countries.

Countries that consistently performed the G-to-G model are Japan and South Korea. It has been noted that the placement of migrant workers to South Korean was conducted through several steps where the model selection was done with an open examination so that everyone has an equal access to become a migrant worker in South Korea. In fact, South Korea has become one of the favorite destinations because of its relatively higher income as compared to other destinations. In addition, the types of jobs available in South Korea encompass jobs in the formal sector so migrant workers feel better legal protection.

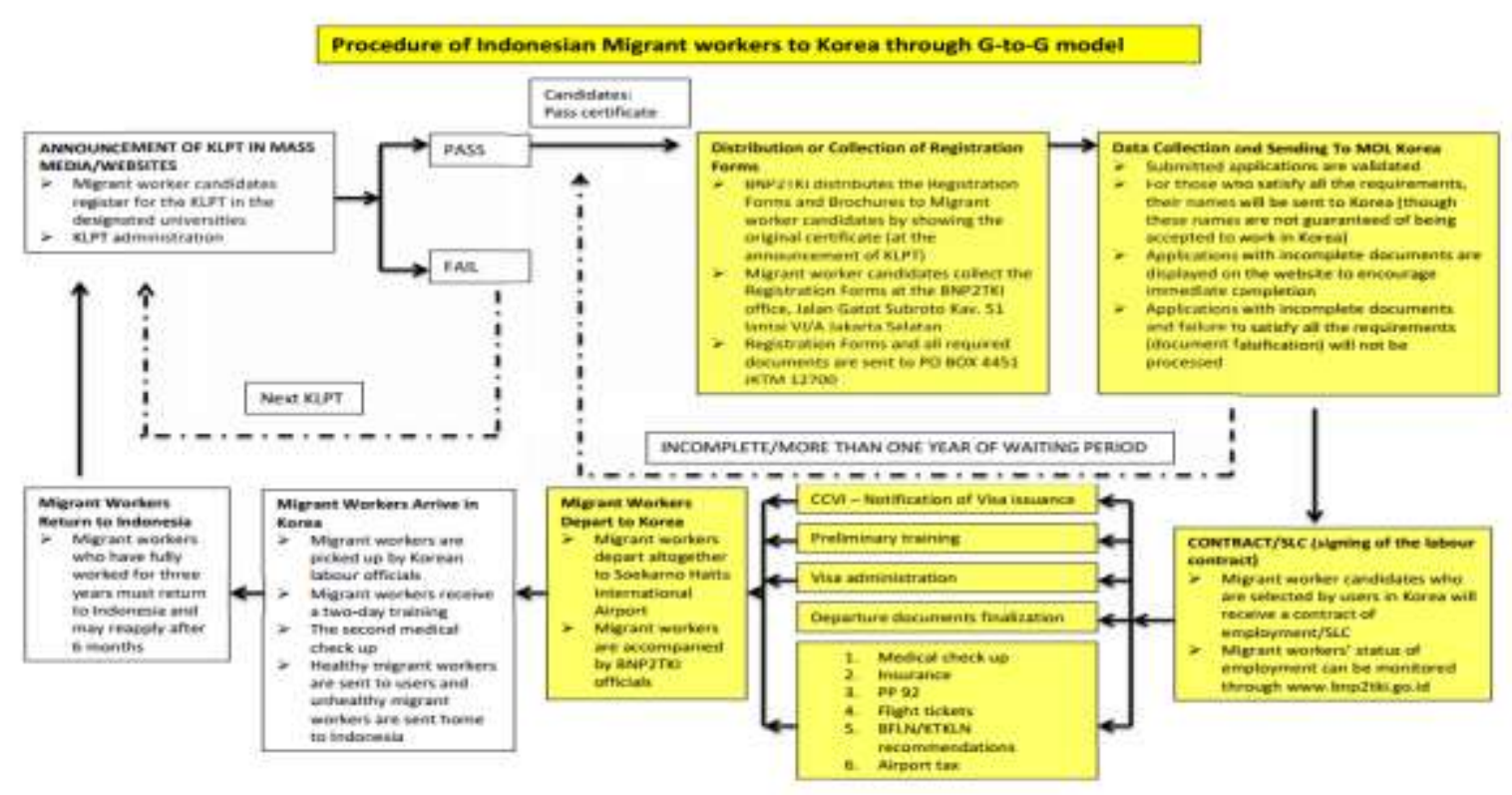

Figure 2. The placement model of migrant workers in South Korean Source : BNP2TKI, 2013

The placement model of migrant workers to South Korean may serve as the main model for the Indonesian government. This model has been evaluated as a means for authorities to revisit before making the decision to send migrant workers out to destination countries. The evaluation was conducted by using qualitative discussions and in-depth interviews with relevant stakeholders. Below are the problems encountered when evaluating this model. It was found that not all destination countries were willing to be directly involved in the placement of migrant workers in their country. There are a number of reasons:

1. Communication skill has become the main requirement for entry into the country of destination; 
2. Competency test systems are still vulnerable to violations; and

3. Placement procedure requires a relatively long time.

All these issues must be resolved by the home government in accordance with Law No. 39 of 2004 on migrant workers. The law instructs the state to provide protection to migrant workers during the pre-placement, placement, and post-placement phases. The proposed recommendation is thus to include the following materials into the laws and regulations governing migrant workers:

1. Start an intense approach with the destination countries in order to change the pattern of employment in the informal sector, as is done in Taiwan and Hong Kong, which provides special working hours and holidays for domestic workers.

2. Organize the training curriculum developed by the PPTKIS. Language needs to become the focus as language skills would be the first step towards improving performance quality.

3. Change the paper-based test to computer-based test which will expand access and provide a more accurate assessment.

4. Propose a cooperation agreement to shorten the pre-placement process for migrant workers.

\section{Conclusion}

Based on the outcome of the study, there are several conclusions to be drawn. They are:

(1) The main priority factors that influence the success of the TKI is by using the AHP model at the point of placement for migrant workers. This is then to be followed by the pre-placement and after placement phases. The period of placement is a top priority because it is the most important moment that will determine the success of the TKI.

(2) The period of the placement will be successful if the home government evaluates the existing placement patterns. There are three main models namely G to G, G to B and B to B. The model that is deemed safest and greatest in increasing the success of the TKI is the G to G model which has been used by the government in the case of South Korea. This is the main model recommended in this study because it seems to work well for both the migrant workers and the government. This model, when implemented can ensure a better welfare of the migrant workers. Thus, the $\mathrm{G}$ to $\mathrm{G}$ model should be formulated in policies and government regulations.

\section{References}

BNP2TKI, 2015. Data Penempatan dan Perlindungan Tenaga Kerja Indonesia tahun 2014, JAKARTA.

Bouguen, A., Filmer, D., Macours, K., \& Naudeau, S. (2014). Preschools and early childhood development in a second best world: Evidence from a scaled-up experiment in Cambodia.

Dequiedt, V. \& Zenou, Y., (2013). International migration, imperfect information, and brain drain. Journal of Development Economics, 102, pp.62-78. Available at: http://dx.doi.org/10.1016/j.jdeveco.2013.02.002.

Dustmann, C. \& Glitz, A., (2011). Chapter 4 - Migration and Education, Available at: http://dx.doi.org/10.1016/B9780-444-53444-6.00004-3.

Dustmann, C., Fadlon, I., \& Weiss, Y. (2011). Return migration, human capital accumulation and the brain drain. Journal of Development Economics, 95(1), 58-67.

Dustmann, C. \& Kirchkamp, O., (2002). The optimal migration duration and activity choice after re-migration. Journal of Development Economics, 67(2), 351-372.

Hugo, G., (1998). The demographic underpinnings of current and future international migration in Asia. Asian and Pacific Migration Journal, 7(1), 1-25.

Hugo, G., (1993). Theories of Internatonal Migration.

Imai, K. S., Gaiha, R., Ali, A., \& Kaicker, N. (2014). Remittances, growth and poverty: NEW evidence from Asian countries. Journal of Policy Modeling, 36(3), 524-538. DOI: 10.1016/j.jpolmod.2014.01.009

IOM, (2010). Remittances and Investment Opportunities for Egyptian Migrants, Cairo.

King, R., (2012). Theories and typologies of migration: An overview and a primer. Willy Brandt Series of Working Papers in International Migration and Ethnic Relations, 3/12, 1-43. 
Lueth, E. \& Ruiz-Arranz, M., (2006). A Gravity Model of Workers 'Remittances. IMF Working Paper - Asia and Pacific Department, 06.

Marchand, K., Sonja, F. \& Siegel, M., (2013). Migrant and Entrepreneurship, Remittances and Development. , (May), 1 -12 .

Massey, D.S., (1999). International Migration at the Dawn of The Twenty-First Century The Role of The state. Population and Development Review 25(2) 303-322.

Massey, D S., Arango, J., Hugo, G., Kouaouci, A., Pellegrinoand, A., \& Taylor, J. E., (1993). Theories of International A Review Migration: and Appraisal. Population English Edition, 19(3), pp.431-466. Available at: http://www.jstor.org/pss/2938462.

Pinger, P., (2010). Come back or stay? Spend here or there? Return and remittances: The case of Moldova. International Migration, 48(5), 142-173.

Presbitero, A.F., Bettin, G. \& Spatafora, N., (2014). Remittances and Vulnerability in Developing Countries. the World bank, (March).

Roy, A., (1951). Some thoughts on the distribution of earnings. Oxford Economic Papers 3, 135-146.

Taylor, J.E., (2006). International migration and economic development. In International symposium on international migration and development, 28(June), p.30. 